\title{
Front Matter: Volume 6785
}

, "Front Matter: Volume 6785," Proc. SPIE 6785, ROMOPTO 2006: Eighth Conference on Optics, 678501 (11 September 2007); doi: 10.1117/12.755472

SPIE. Event: ROMOPTO 2006: Eighth Conference on Optics, 2006, Sibiu, Romania 


\title{
PROCEEDINGS OF SPIE
}

\section{ROMOPTO 2006:}

\section{Eighth Conference on Optics}

\section{Valentin I. Vlad}

Editor

\section{4-7 September 2006 \\ Sibiu, Romania}

\author{
Organized by \\ Romanian Physical Society, Division of Optics and Quantum Electronics - SPIE Romanian \\ Chapter • ROCEP—National Institute for Laser, Plasma and Radiation Physics (Romania) \\ INOE 2000-National Institute for Research and Development for Optoelectronics (Romania) \\ University of Bucharest, Faculty of Physics (Romania) - University Lucian Blaga of Sibiu, \\ Hermann Oberth Faculty of Engineering (Romania) \\ Cosponsored by \\ Romanian Academy, Division of Physics - Ministry of Education and Research (Romania) \\ PhOREMOST European Network of Excellence, Nanophotonics to Realise Molecular Scale \\ Technologies - OSA_Optical Society of America - SPIE Europe - EOARD—European Office of \\ Aerospace Research and Development - ICTP-The Abdus Salam International Centre for \\ Theoretical Physics (Italy) • ICO_International Commission for Optics • EOS-European \\ Optical Society • Institute of Atomic Physics (Romania) \\ Published by \\ SPIE
}

Volume 6785 
The papers included in this volume were part of the technical conference cited on the cover and title page. Papers were selected and subject to review by the editors and conference program committee. Some conference presentations may not be available for publication. The papers published in these proceedings reflect the work and thoughts of the authors and are published herein as submitted. The publisher is not responsible for the validity of the information or for any outcomes resulting from reliance thereon.

Please use the following format to cite material from this book:

Author(s), "Title of Paper," in ROMOPTO 2006: Eighth Conference on Optics, edited by Valentin I. Vlad, Proceedings of SPIE Vol. 6785 (SPIE, Bellingham, WA, 2007) Article CID Number.

ISSN 0277-786X

ISBN 9780819469496

Published by

SPIE

P.O. Box 10, Bellingham, Washington 98227-0010 USA

Telephone +1 3606763290 (Pacific Time) · Fax +1 3606471445

SPIE.org

Copyright (C 2007, Society of Photo-Optical Instrumentation Engineers

Copying of material in this book for internal or personal use, or for the internal or personal use of specific clients, beyond the fair use provisions granted by the U.S. Copyright Law is authorized by SPIE subject to payment of copying fees. The Transactional Reporting Service base fee for this volume is $\$ 18.00$ per article (or portion thereof), which should be paid directly to the Copyright Clearance Center (CCC), 222 Rosewood Drive, Danvers, MA 01923. Payment may also be made electronically through CCC Online at copyright.com. Other copying for republication, resale, advertising or promotion, or any form of systematic or multiple reproduction of any material in this book is prohibited except with permission in writing from the publisher. The CCC fee code is $0277-786 \mathrm{X} / 07 / \$ 18.00$.

Printed in the United States of America.

Publication of record for individual papers is online in the SPIE Digital Library.

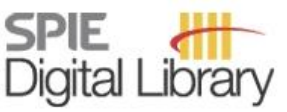

SPIEDigitallibrary.org

Paper Numbering: Proceedings of SPIE follow an e-First publication model, with papers published first online and then in print and on CD-ROM. Papers are published as they are submitted and meet publication criteria. A unique, consistent, permanent citation identifier (CID) number is assigned to each article at the time of the first publication. Utilization of CIDs allows articles to be fully citable as soon they are published online, and connects the same identifier to all online, print, and electronic versions of the publication. SPIE uses a six-digit CID article numbering system in which:

- The first four digits correspond to the SPIE volume number.

- The last two digits indicate publication order within the volume using a Base 36 numbering system employing both numerals and letters. These two-number sets start with 00, 01, 02, 03, 04, 05, $06,07,08,09,0 A, 0 B \ldots 0 Z$, followed by $10-12,20-2 Z$, etc.

The CID number appears on each page of the manuscript. The complete citation is used on the first page, and an abbreviated version on subsequent pages. Numbers in the index correspond to the last two digits of the six-digit CID number. 


\title{
Contents
}

\author{
xiii Conference Committees \\ xv Introduction \\ xvii Organizers and Cosponsors \\ xix New optical components based on nano-scale features (Abstract Only) \\ M. J. Soileau, Univ. of Central Florida (USA) \\ Xx Semiconductor pumped cw solid-state lasers in the visible and UV spectral region \\ (Abstract Only) \\ G. Huber, Institut für Laser-Physik, Univ. Hamburg (Germany) \\ xxi Inorganic nanotubes and inorganic fullerene-like materials: state of the art, from concept \\ to applications (Abstract Only) \\ R. Tenne, Weizmann Institute (Israel) \\ xxii Advances in mapping and steering of functional organic molecules by nonlinear optics \\ from micron to single molecule scale (Abstract Only) \\ J. Zyss, G. Dutier, S. Brasselet, Molecular Quantum Photonics Lab. and d'Alembert Institute, \\ Ecole Normale Supérieure (France)
}

\section{PLENARY PAPER}

678502 Bright new world: a new type of light and its applications (Plenary Paper) [6785-01]

N. Kroo, Hungarian Academy of Sciences (Hungary)

\section{SESSION $1 \quad$ LASERS AND RADIATION SOURCES}

$678503 \mathrm{Yb}^{3+}$-doped $\mathrm{CaF}_{2}$ cubic fluoride crystal: spectroscopic properties, concentration quenching analysis, and laser optimization (Invited Paper) [6785-02] G. Boulon, M. Ito, Y. Guyot, C. Goutaudier, A. Brenier, Claude Bernard/Lyon I Univ., CNRS (France); A. Jouini, H. Sato, T. Fukuda, Tohoku Univ. (Japan)

678504 Diode pumped neodymium-based thin disk lasers [6785-03] N. Pavel, Univ. Hamburg (Germany) and National Institute for Laser, Plasma and Radiation Physics (Romania); K. Lünstedt, K. Petermann, G. Huber, Univ. Hamburg (Germany)

678505 Modelling and evaluation of some spectroscopic parameters of $\mathrm{Er}^{3+}$ and $\mathrm{Yb}^{3+}$-doped $\mathrm{LiNbO}_{3}$ optical waveguide amplifiers [6785-04]

G. C. Constantin, N. N. Puscas, I. M. Popescu, Univ. Politehnica of Bucharest (Romania)

678506 Nonlinear mirror mode locking operation of edge pumped Yb:YAG/YAG laser [6785-05] T. Dascalu, National Institute for Lasers, Plasma and Radiation Physics (Romania); T. Taira, Institute for Molecular Science (Japan) 
678507 Generation of a radially polarized Nd:YVO 4 laser beam [6785-06]

K. Yonezawa, Y. Kozawa, T. Nakamura, S. Sato, Tohoku Univ. (Japan)

678508 Single frequency green nanosecond Nd:YAG microlaser-oscillator power-amplifier system [6785-07]

R. Dabu, C. Blanaru, A. Stratan, O. Pacala, C. Fenic, L. Neagu, L. Rusen, National Institute for Lasers, Plasma and Radiation Physics (Romania); D. Ursu, ProOptica (Romania);

V. Tornari, Y. Orphanos, Foundation for Research and Technology, Institute of Electronic

Structure and Laser (Greece)

678509 Optical studies of the partially disordered crystals langasite $\left(\mathrm{La}_{3} \mathrm{Ga}_{5} \mathrm{SiO}_{14}\right)$ and langatate $\left(\mathrm{La}_{3} \mathrm{Ga}_{5.5} \mathrm{Ta}_{0.5} \mathrm{O}_{14}\right)$ doped with $\mathrm{Eu}^{3+}$ [6785-08]

S. Georgescu, O. Toma, A. Achim, A. M. Chinie, L. Gheorghe, A. Stefan, National Institute for Laser, Plasma, and Radiation Physics (Romania)

6785 0A Optical and Mössbauer studies on YAG:Eu nanocrystals synthesized by a sol-gel method [6785-09]

S. Georgescu, National Institute for Laser, Plasma and Radiation Physics (Romania);

S. Constantinescu, National Institute for Materials Physics (Romania); A. M. Chinie,

A. S. Stefan, O. Toma, National Institute for Laser, Plasma and Radiation Physics (Romania); I. Bibicu, National Institute for Materials Physics (Romania)

6785 OB High-power lens-shape diode edge-pumped composite laser [6785-10]

T. Dascalu, National Institute for Lasers, Plasma and Radiation Physics (Romania);

C. Dascalu, Univ. Politehnica Bucharest (Romania)

6785 OC Spectroscopic characteristics of $\mathrm{RE}^{3+}: \mathrm{Sc}_{2} \mathrm{O}_{3}$ ceramics [6785-11]

V. Lupei, A. Lupei, C. Gheorghe, Institute of Atomic Physics-INFLPR (Romania); A. Ikesue, Poly-Techno Co., Ltd. (Japan); A. Stefan, Institute of Atomic Physics-INFLPR (Romania);

V. Ciupina, A. Prodan, Univ. Ovidius (Romania)

6785 OD A schematic layout of the magnetic field for a two-beam Huygens undulator [6785-12] S. Miclos, M. I. Rusu, C. Radu, V. Savu, National Institute of R\&D for Optoelectronics (Romania); L. Giurgiu, Univ. of Bucharest (Romania); V. I. R. Niculescu, National Institute of R\&D for Lasers, Plasma and Radiation Physics (Romania)

\section{SESSION 2 LASERS IN MATERIAL SCIENCES}

$6785 \mathrm{OE}$ Thin film synthesis of wurtzite boron nitride by femtosecond pulsed laser deposition (Invited Paper) [6785-13]

T. Shimizu, T. Nakamura, S. Sato, Tohoku Univ. (Japan)

6785 OF Influence of irradiation conditions on plume expansion induced by femtosecond laser ablation of gold and copper (Invited Paper) [6785-14]

S. Noël, J. Hermann, LP3, CNRS, Univ. Aix-Marseille II (France) 
6785 OG Chemical sensors based on optical sensitivity of metal oxide materials deposited on multimode interference couplers [6785-15]

T. Mazingue, Univ. Montpellier II (France); R. Kribich, J. Jabbour, S. Gatti, Ctr. d'Electronique et de Micro-optoélectronique de Montpellier, CNRS, Univ. Montpellier II (France);

L. Escoubas, Institut Fresnel, CNRS, Domaine Univ. de Saint Jérôme (France); I. Mihalescu, National Institute for Lasers, Plasma and Radiation Physics (Romania); P. Etienne, Univ. Montpellier II (France); Y. Moreau, Ctr. d'Electronique et de Micro-optoélectronique de Montpellier, CNRS, Univ. Montpellier II (France); F. Flory, Institut Fresnel, CNRS, Domaine Univ. de Saint Jérôme (France)

$6785 \mathrm{OH} \quad$ Structure and optical properties of pulsed-laser-deposited AIN thin films for optoelectronic applications [6785-16]

S. Bakalova, A. Szekeres, Institute of Solid State Physics (Bulgaria); A. Cziraki, Eotvos Lorand Univ. (Hungary); S. Grigorescu, G. Socol, E. Axente, I. N. Mihailescu, National Institute for Lasers, Plasma and Radiation Physics (Romania)

6785 Ol Triple bound states of the cubic-quintic CGL equation: the "Cis" symmetry [6785-17] H. Leblond, A. Komarova, M. Salhi, A. Haboucha, F. Sanchez, Lab. POMA, Univ. d'Angers (France)

6785 0J Quantum dot-based western blot for sensitive detection of pig serum antibody to Actinobacillus pleuropneumoniae [6785-18]

A. Cişmileanu, Pasteur Institute (Romania); C. Sima, C. Grigoriu, National Institute for Laser, Plasma and Radiation Physics (Romania)

6785 OK Functionalized $\mathrm{Si} / \mathrm{SiO}_{2}$ quantum dots [6785-19]

C. Sima, C. Viespe, I. Nicolae, C. Grigoriu, National Institute of Laser, Plasma and Radiation Physics (Romania); G. Prodan, V. Ciupina, Ovidius Univ. Constanta (Romania);

A. Cismileanu, Pasteur Institute (Romania); C. Nistor, C. Nicolae, D. Donescu, ICECHIM (Romania)

$6785 \mathrm{OL}$ Preliminary studies concerning Hadfield steel behavior during laser beam welding in pulsating regime [6785-20]

I. David, V.-A. Şerban, Univ. Politehnica of Timisoara (Romania)

\section{SESSION 3 NANOPHOTONICS}

6785 OM Colloidal nanocrystals: on the way from synthesis to applications (Invited Paper) [6785-21] N. Gaponik, A. Eychmüller, Technical Univ. Dresden (Germany)

6785 ON Photosensitive composites based on chalcogenide glasses and organic polymers (Invited Paper) [6785-22]

A. M. Andries, V. V. Bivol, S. A. Buzurniuc, E. P. Colomeico, M. S. Iovu, A. lu. Meshalkin, V. I. Verlan, Institute of Applied Physics (Moldova)

678500 Controlled deposition of photonic polystyrene-nanosphere films [6785-23]

A. Kuttesch, C. Farcau, Z. Neda, S. Astilean, Babes-Bolyai Univ. (Romania) 
$6785 \mathrm{OP}$ Electronic and thermal nonlinear refractive indices of SOI and nano-patterned SOI measured by Z-scan method [6785-24]

A. Petris, National Institute for Lasers, Plasma and Radiation Physics (Romania); F. Pettazzi, E. Fazio, Univ. La Sapienza (Italy) and INFM (Italy); C. Peroz, Y. Chen, Lab. de Photonique et de Nanostructures, CNRS (France); V. I. Vlad, National Institute for Lasers, Plasma and Radiation Physics (Romania); M. Bertolotti, Univ. La Sapienza (Italy) and INFM (Italy)

$6785 \mathrm{OQ}$ The behavior of three quantum radiators in microcavity [6785-25]

N. Enaki, T. Roşca, Institute of Applied Physics (Moldova)

6785 OR What is a quantum particle? [6785-26]

A. Lupascu, Politehnica Univ. Bucharest (Romania)

6785 OS Reversibility of quantum states for non-equidistant three-level atom in interaction with bimodal cavity field [6785-27]

N. A. Enaki, N. Ciobanu, Institute of Applied Physics (Moldova)

6785 ОT Confocal microscopy for visualization and characterization of porous silicon samples [6785-28]

P. Doia, A. Petris, I. Dancus, V. I. Vlad, National Institute for Lasers, Plasma and Radiation Physics (Romania)

$6785 \mathrm{OU}$ Laser induced reorientation process in dye-doped nematic systems: role of the azo-dye structure [6785-29]

N. Eseanu, C. Dascalu, Univ. Politehnica of Bucharest (Romania); I. Palarie, Univ. of Craiova (Romania); C. Uncheselu, Technical Univ. of Civil Engineering (Romania)

\section{SESSION 4 NON-LINEAR AND INFORMATION OPTICS}

$6785 \mathrm{OV}$ On some physical properties of a new photopolymerisable glass with high refractive index species for holographic data storage (Invited Paper) [6785-30]

M. L. Calvo, Univ. Complutense de Madrid (Spain); P. Cheben, National Research Council of Canada (Canada); O. Martínez-Matos, J. A. Rodrigo, Univ. Complutense de Madrid (Spain); F. del Monte, Instituto de Ciencia de Materiales de Madrid, CSIC-UAM (Spain)

6785 OW Fourier domain spatio-temporal visualization using image processing methods (Invited Paper) [6785-31]

A. Peled, N. Mirchin, Holon Institute of Technology (Israel)

6785 0X Transmission of solitary pulses in inhomogeneous nonlinear media: exact solutions (Invited Paper) [6785-32]

K. W. Chow, Univ. of Hong Kong (Hong Kong China); B. A. Malomed, Tel Aviv Univ. (Israel)

6785 OY Few-cycle solitons in a two-component medium (Invited Paper) [6785-33]

H. Leblond, Lab. POMA, CNRS, Univ. d'Angers (France); S. V. Sazonov, Russian Research Ctr. Kurchatov Institute (Russia); I. V. Mel'nikov, High Q Labs. Inc. (Canada) and Optolink Ltd. (Russia); D. Mihalache, Horia Hulubei National Institute for Physics and Nuclear Engineering, IFIN-HH (Romania); F. Sanchez, Lab. POMA, CNRS, Univ. d'Angers (France) 
$67850 Z$ Soliton dynamics and interactions in dynamically photo-induced lattices (Invited Paper) [6785-34]

I. Tsopelas, Y. Kominis, K. Hizanidis, N. Efremidis, S. Droulias, L. Halastanis, G. Papazisimos, N. Moshonas, P. Papagiannis, National Technical Univ. of Athens (Greece)

678510 Three-dimensional spinning solitons in quasi-two-dimensional optical lattices [6785-35] H. Leblond, Lab. POMA, Univ. d'Angers (France); B. A. Malomed, Tel Aviv Univ. (Israel); D. Mihalache, Horia Hulubei National Institute for Physics and Nuclear Engineering, IFIN-HH (Romania)

678511 Stable multidimensional dissipative spiral solitons [6785-36]

D. Mihalache, Horia Hulubei National Institute for Physics and Nuclear Engineering, IFIN-HH (Romania) and Friedrich-Schiller Univ. Jena (Germany)

678512 Fast adaptive interferometer based on CdTe crystal and low power radiation [6785-37] R. V. Romashko, Y. N. Kulchin, Institute of Automation and Control Processes (Russia); S. Di Giloramo, E. Nippolainen, Univ. of Kuopio (Finland); J. C. Launay, CNRS, Bordeaux Institute of Condensed Matter Chemistry (France); A. A. Kamshilin, Univ. of Kuopio (Finland)

678513 Iterative algorithm analysis for phase-only diffractive control access system [6785-38] M. Mihailescu, A. Preda, Univ. Politehnica of Bucharest (Romania); D. Cojoc, TASC-NNLINFM, National Institute for the Physics of Matter (Italy); E. Scarlat, L. Preda, Univ. Politehnica of Bucharest (Romania)

678514 Three-dimensional vortex solitons in self-defocusing media [6785-39]

N. K. Efremidis, National Technical Univ. of Athens (Greece) and Univ. of Crete (Greece); Y. Kominis, N. Moshonnasa, P. Papagiannis, K. Hizanidis, National Technical Univ. of Athens (Greece); B. A. Malomed, Tel Aviv Univ. (Israel); P. Di Trapani, Univ. of Insubria (Italy)

678515 Second harmonic generation in self-induced waveguides in lithium niobate [6785-40] F. Pettazzi, Univ. La Sapienza e CNISM (Italy) and Univ. de Franche-Comté, Institut FEMTOST, CNRS (France); V. Coda, M. Chauvet, Univ. de Franche-Comté, Institut FEMTO-ST, CNRS (France); E. Fazio, Univ. La Sapienza e CNISM (Italy)

678516 Theoretical analysis of the spectral gain and noise of single and double pass $\mathrm{Er}^{3+}$-doped Ti:LiNbO 3 straight waveguide amplifiers [6785-41]

B. Savu, N. N. Puscas, Univ. Politehnica of Bucharest (Romania)

678517 Corrugated grating on organic multilayer Bragg reflector [6785-42]

S. Jaquet, T. Scharf, H. P. Herzig, Univ. of Neuchâtel (Switzerland)

678518 Interplay between photonic and plasmonic modes in optical properties of silver-coated two dimensional colloidal crystals [6785-43]

C. Farcau, A. Kuttesch, Babes-Bolyai Univ. (Romania); T. Petrisor, Technical Univ. ClujNapoca (Romania); L. Barbu-Todoran, C. Craciun, S. Astilean, Babes-Bolyai Univ. (Romania)

678519 Absorption and photoluminescence of $\mathrm{Ga}_{0.017} \mathrm{Ge}_{0.25} \mathrm{As} 0.083 \mathrm{~S}_{0.65}$ glasses doped with rareearth ions [6785-44]

M. S. Iovu, A. M. Andriesh, E. V. Lupan, V. I. Ciornea, N. N. Syrbu, Ctr. of Optoelectronics, IAP (Moldova) 
6785 IA Multiple trapping and micromanipulation of dielectric particles with optical tweezers [6785-45]

M. Nadasan, Laser and Fiber Optics Lab. (Italy); A. Manea, I. Cristea, N. Grosu, O. Iancu, Politehnica Univ. of Bucharest (Romania)

6785 1B Reflection coefficients for photonic crystal waveguides ramifications [6785-46]

L. Bogdan, P. Sterian, Bucharest Polytechnic Univ. (Romania)

$67851 \mathrm{C}$ Fast photorefractive self-focusing in semiconductors [6785-47]

C. Dan, N. Khelfaoui, D. Wolfersberger, N. Fressengeas, Lab. Matériaux Optiques, Photonique et Systémes, CNRS (France); H. Leblond, Lab. Propriétés Optiques des Matériaux et Applications, CNRS (France); M. Chauvet, Institut Femto-ST, CNRS (France)

6785 ID Optical field properties in micro- and nano-structures [6785-48]

G. Georgescu, National Institute for Lasers, Plasma and Radiation Physics (Romania); V. Babin, National Institute for Optoelectronics (Romania); R. Medianu, National Institute for Lasers, Plasma and Radiation Physics (Romania)

$6785 \mathrm{IE}$ Modification of refractive index in amorphous As-Se films induced by composition and illumination [6785-49]

M. S. Iovu, D. V. Harea, E. P. Colomeico, M. A. lovu, V. G. Ciorba, Ctr. of Optoelectronics, IAP, ASM (Moldova)

6785 IF Z-Scan measurement of thermal optical nonlinearities [6785-50]

I. Dancus, A. Petris, P. Doia, National Institute for Lasers, Plasma and Radiation Physics (Romania); E. Fazio, Univ. La Sapienza (Italy); V. I. Vlad, National Institute for Lasers, Plasma and Radiation Physics (Romania)

\section{SESSION 5 BIOPHOTONICS AND OPTICS IN ENVIRONMENT RESEARCH}

6785 IG Inorganic and hybrid polymer-inorganic nanostructured materials for optical physicochemical sensing applications (Invited Paper) [6785-51]

A. Tsigara, The National Hellenic Research Foundation (Greece) and The National Technical Univ. of Athens (Greece); L. Athanasekos, J. Manasis, M. Hands, G. Mousdis, S. Pispas, The National Hellenic Research Foundation (Greece); N. A. Vainos, The National Hellenic Research Foundation (Greece) and Univ. of Patras (Greece)

6785 1H UV-B radiation induced effects on human T-lymphocytes (Invited Paper) [6785-52] G. Giubileo, ENEA (Italy); A. Congiu Castellano, S. Gaudenzi, P. Grimaldi, D. Pozzi, Univ. di Roma La Sapienza (Italy); A. Puiu, National Institute for Laser, Plasma and Radiation Physics (Romania)

678511 Optical-coherence tomography: extension to imaging of low coherence interferometry (Invited Paper) [6785-53]

A. Gh. Podoleanu, R. G. Cucu, Univ. of Kent (United Kingdom); J. A. Rogers, J. Pedro, Ophthalmic Technologies Inc. (Canada); G. Dobre, M. Gomez, Univ. of Kent (United Kingdom); H. Liang, Nottingham Trent Univ. (United Kingdom); B. T. Amaechi, The Univ. of Texas Health Sciences Ctr. at San Antonio (USA); S. Higham, Univ. of Liverpool (United Kingdom) 
$6785 \mathrm{IJ} \mathrm{Modeling} \mathrm{vegetation} \mathrm{reflectance} \mathrm{from} \mathrm{satellite} \mathrm{remote} \mathrm{sensing} \mathrm{data} \mathrm{[6785-54]}$ M. Zoran, National Institute of R\&D for Optoelectronics (Romania)

6785 IK Using RWMCS to test different multiple light scattering phase functions for biological suspensions [6785-55]

D. Chicea, Univ. Lucian Blaga (Romania)

$6785 \mathrm{lL}$ Modeling influences of topography on incoming solar radiation from satellite remote sensing data [6785-56]

M. Zoran, National Institute of R\&D for Optoelectronics (Romania)

$67851 \mathrm{M}$ Influence of laser diode red beams on germination rate of tomato seeds [6785-57]

P. Niculita, S. Danaila-Guidea, O. Livadariu, M. Popa, USAMV (Romania); M. Ristici, E. Ristici, 4ROPTICS (Romania)

6785 iN High-power LEDs influence on germination rate of tomato seeds [6785-58]

C. Tudora, National Institute of R\&D for Biological Sciences INCDSB (Romania); M. Ristici,

E. Ristici, S.C. 4R OPTICS (Romania)

678510 Results of sediment motion visualization by a modified LASCA technique [6785-59]

D. Chicea, Univ. Lucian Blaga (Romania)

6785 IP A special laser device for dielectric breakdown generation used in ophthalmology [6785-60]

D. Savastru, E. Ristici, M. Mustata, S. Miclos, M. Rusu, V. Savu, C. Radu, D. Tenciu, National Institute of R\&D for Optoelectronics (Romania)

$67851 Q \quad$ Novel approaches in the designing of the polygon scanners (Invited Paper) [6785-61]

V.-F. Duma, Aurel Vlaicu Univ. (Romania)

6785 IR Refractive index of micro/nano structured dielectric materials (Invited Paper) [6785-62]

F. Flory, L. Escoubas, J. J. Simon, P. Torchio, T. Mazingue, T. Mangeat, Univ. Paul Cézanne (France)

6785 is Thin-film graded optical filters for mini-spectrometers (Invited Paper) [6785-63]

A. Piegari, J. Bulir, A. Krasilnikova Sytchkova, ENEA (Italy)

6785 IT Study of color centers in optical fibers to be used for ITER plasma diagnostics [6785-64]

D. G. Sporea, A. Sporea, National Institute for Lasers, Plasma and Radiation Physics

(Romania); S. Agnello, L. Nuccio, Univ. of Palermo (Italy)

$67851 \mathrm{U}$ Extracurricular photonics education in Romanian high schools [6785-65]

D. Sporea, A. Sporea, C. Timus, National Institute for Lasers, Plasma and Radiation Physics (Romania) 
6785 IV Characterization of surface relief gratings of submicron period [6785-66]

P. C. Logofătu, D. Apostol, National Institute for Lasers, Plasma and Radiation Physics

(Romania); M.-C. Castex, Lab. de Physique des Lasers, Univ. Paris-Nord (France); I. Apostol, V. Damian, I. Iordache, National Institute for Lasers, Plasma and Radiation Physics

(Romania); R. Müller, National Institute in Microtechnologies (Romania)

6785 IW Double-prisms neutral density filters: a comparative approach [6785-67]

V.-F. Duma, Aurel Vlaicu Univ. (Romania)

$67851 \mathrm{X}$ Optical studies of $\mathrm{TiO}_{2}$ films deposited on different substrates [6785-68]

C. Cotîrlan, V. Vasile, F. Ungureanu, National Institute of Materials Physics (Romania)

$6785 \mathrm{IY}$ Effect of heat treatment on the structural and optical characteristics of polycrystalline ZnTe thin films [6785-69]

P. Prepeliță, G. G. Rusu, G. I. Rusu, Al. I. Cuza Univ. (Romania)

678512 Ultrasonic waves generated by laser based heat sources in semitransparent solids [6785-70]

L. Bogdan, A. R. Sterian, D. Nedelcu, Bucharest Polytechnic Univ. (Romania)

678520 An Er:YAG blood sampling skin puncher [6785-71]

D. Savastru, E. Ristici, M. Mustata, S. Miclos, M. Rusu, C. Radu, V. Savu, National Institute of R\&D for Optoelectronics (Romania)

$678521 \quad$ Static Fourier transform lambdameter [6785-72]

D. Apostol, A. Sima, P. C. Logofătu, F. Garoi, V. Damian, V. Nascov, I. lordache, National Institute for Laser, Plasma and Radiation Physics (Romania)

678522 Fourier transform digital holography [6785-73]

D. Apostol, A. Sima, P. C. Logofătu, F. Garoi, V. Damian, V. Nascov, I. lordache, National Institute for Laser Plasma and Radiation Physics (Romania)

678523 Magnetic liquid surface behaviour to external stimulus [6785-74]

V. Damian, P. C. Logofatu, D. Apostol, National Institute for Laser Plasma and Radiation Physics (Romania); L. Vekas, D. Bica, Ctr. for Fundamental and Advanced Technical Research (Romania); A. Damian, Polytechnic Univ. (Romania); F. Garoi, I. Iordache, A. Sima, M. Bojan, National Institute for Laser Plasma and Radiation Physics (Romania)

678524 Radio frequency magnetron sputtering deposition of borate and phosphate glass films [6785-75]

L. Boroica, I. Boroica, E. Rotiu, B. Sava, National Glass Institute (Romania); R. Medianu,

C. Timus, National Institute for Laser, Plasma and Radiation Physics (Romania);

D. Hülsenberg, Technical Univ. IImenau (Germany)

678525 Acquisition and applications of 3D images [6785-76]

P. Sterian, E. Mocanu, Bucharest Polytechnic Univ. (Romania)

678526 Study of surface and bulk ultrasonic waves generated in solids numerical analysis [6785-77]

L. Bogdan, A. R. Sterian, D. Nedelcu, Bucharest Polytechnic Univ. (Romania) 
678527 Optical models used for the study of laser beam [6785-78]

P. Valentin, N. Toderița, P. Florian, Univ. Lucian Blaga of Sibiu (Romania)

678528 Measurement methods of laser beam parameters [6785-79]

P. Florian, Univ. Lucian Blaga of Sibiu (Romania); G. G. Titus, RELEE S.A. (Romania)

Author Index 
Downloaded From: https://www.spiedigitallibrary.org/conference-proceedings-of-spie on 26 Apr 2023

Terms of Use: https://www.spiedigitallibrary.org/terms-of-use 


\section{Conference Committees}

\section{Conference Chair}

Valentin I. Vlad, National Institute for Lasers, Plasma and Radiation Physics (Romania)

Scientific Committee

\begin{tabular}{|l|l|l|l|}
\hline M. Bertolotti, & & & \\
Coordinator & (Italy) & V. I. Konov & (Russia) \\
G. Badenes & (Spain) & N. Kroo & (Hungary) \\
G. von Bally & (Germany) & M. Kujawinska & (Poland) \\
J. Bilbro & (USA) & F. Lederer & (Germany) \\
A. D. Boardman & (United Kingdom) & C. Lopez & (Spain) \\
P. Chavel & (Spain) & M. Malvezzi & (Italy) \\
Anna Consortini & (France) & A. Peled & (Israel) \\
J. C. Dainty & (Italy) & I. I. Popescu & (Romania) \\
R. De La Rue & (Ireland) & H. Rajbenbach & (France) \\
G. Denardo & (United Kingdom) & Roberta Ramponi & (Italy) \\
A. Dogariu & (Italy) & G. Righini & (Italy) \\
H. J. Eichler & (USA) & M. Scully & (USA) \\
C. Flytzanis & (Germany) & A. Serpenguzel & (Turkey) \\
C. Fotakis & (France) & Clivia Sotomayor-Torres & (Ireland) \\
N. Fressengeas & (Greece) & M. Segev & (Israel) \\
A. A. Friesem & (France) & M. Stickley & (USA) \\
A. T. Friberg & (Israel) & T. Tschudi & (Germany) \\
J. W. Goodman & (Sweden) & I. Ursu & (Romania) \\
R. Grigorovici & (USA) & N. Vainos & (Greece) \\
J. P. Huignard & (Romania) & H. Walther & (Germany) \\
Y. Kivshar & (France) & F. Wise & (USA) \\
\hline
\end{tabular}

Programme Committee

\begin{tabular}{|l|l|l|l|}
\hline V. I. Vlad, Coordinator & (Romania) & E. Marom & (Israel) \\
E. Arthurs & (USA) & R. Medianu & (Romania) \\
D. Apostol & (Romania) & I. N. Mihailescu & (Romania) \\
A. Andriesh & (Moldova) & D. Mihalache & (Romania) \\
G. Assanto & (Italy) & I. Morjan & (Romania) \\
S. Astileanu & (Romania) & G. Nemes & (USA) \\
G. Boulon & (France) & K. Peiponen & (Finland) \\
V. Ciupina & (Romania) & E. Ozbay & (Turkey) \\
D. Cojoc & (Romania) & A. Petris & (Romania) \\
V. Craciun & (Romania) & Angela Piegari & (ltaly) \\
\hline
\end{tabular}




\begin{tabular}{|l|l|l|l|}
\hline M. Damzen & (United Kingdom) & A. Podoleanu & (United Kingdom) \\
E. Fazio & (Italy) & N. Puscas & (Romania) \\
F. Flory & (France) & Roxana Savastru & (Romania) \\
S. Georgescu & (Romania) & C. Sheppard & (Australia) \\
C. Grigoriu & (Romania) & Concita Sibilia & (Italy) \\
N. Gaponik & (Germany) & G. Stanciu & (Romania) \\
Margareta Giurgea & (Romania) & P. Sterian & (Romania) \\
I. lova & (Romania) & T. Taira & (Japan) \\
A. Kamshilin & (Finland) & V.I. Topa & (Romania) \\
Isabelle Ledoux & (France) & T. Tudor & (Romania) \\
A. Luches & (Italy) & J. Tsujiuchi & (Japan) \\
A. Lupascu & (Romania) & J. Werckmann & (France) \\
A. Lupei & (Romania) & K. Yatsui & (Japan) \\
V. Lupei & (Romania) & & \\
\hline
\end{tabular}

Organizing Committee

Clementina Timus, Coordinator (Romania)

\begin{tabular}{|l|l|}
\hline V. Babin & (Romania) \\
Tatiana Bazaru & (Romania) \\
Mariana Buzatu & (Romania) \\
I. Dancus & (Romania) \\
T. Dascalu & (Romania) \\
C. Delaney & (Ireland) \\
Petronela Doia & (Romania) \\
\hline
\end{tabular}

\begin{tabular}{|l|l}
\hline S. Georgescu & (Romania) \\
Sinead Kennedy & (Ireland) \\
Doina Nicolae & (Romania) \\
C. Stan & (Romania) \\
Florenta Craciun & (Romania) \\
Camelia Talianu & (Romania) \\
M. Udrea & (Romania) \\
\hline
\end{tabular}

Local Organizing Committee

Ilie Isarie, Coordinator (Romania)

\begin{tabular}{|l|l|l|l|}
\hline $\begin{array}{l}\text { C. L. Isarie } \\
\text { Toderita Nemes }\end{array}$ & (Romania) & $\begin{array}{l}\text { G. Sofonea } \\
\text { V. Chicea }\end{array}$ & (Romania) \\
V. D. Petrescu & (Romania) & & \\
\hline
\end{tabular}

Treasurer

Alexandra Olteanu (Romania) 


\section{Introduction}

The conference on Micro- to Nano-Photonics: ROMOPTO 2006 is the eighth in a series of international conferences dedicated to optics and photonics, held every three years in Romania and initiated by Acad. Prof. Ioan Ursu. The topics of this conference are related to the modern micro- and nano-photonics and reflect the fast evolution of optics and its applications in material science, information science and technology, optoelectronics, biology and medicine, and sensing and metrology. The results in these fields demonstrate the important role of photonics in the progress of the modern society.

The purpose of ROMOPTO 2006 was to provide an opportunity for the optics scientists to share experiences, discuss their newest results, stimulate interdisciplinary research, and consider the perspective of applications. The position of our country, Romania, in the Central-East Europe plays an important role in the promotion of the scientific contacts in this region. We are now integrating into the European Union, NATO, and are actively participating in the EU-R\&D Programmes. In the national strategy in R\&D, photonics plays an important role both in basic research and in technological platforms. I can add the fact that Sibiu, the host town of the conference, and Luxembourg are European capitals of culture in 2007.

The organization of ROMOPTO 2006 was possible only by the actions and support of several national and international institutions. We have to mention and thank the Romanian Academy, the Romanian Ministry of Education and Research, the Division of Optics and Quantum Electronics of the Romanian Physical Society (which is a Territorial Committee of ICO and EOS), the Romanian Chapter of SPIE, the Institute of Atomic Physics, the National Institute of Laser, Plasma and Radiation Physics (NILPRP), the University "Lucian Blaga" of Sibiu, the National Institute of Optoelectronics (NIOE 2000) and the University of Bucharest.

Thanks are due to the cosponsoring institutions of this conference: European Network of Excellence "Nanophotonics to Realise Molecular Scale Technologies" (PHOREMOST), SPIE Europe, the "Abdus Salam" International Centre for Theoretical Physics (ICTP, Trieste, Italy), ICO_International Commission for Optics, OSA-Optical Society of America, EOS-European Optical Society, and the United States Air Force-European Office of Aerospace Research and Development (EOARD). Particularly, I express my entire gratitude to Prof. Clivia Sotomayor-Torres and Prof. E. Ozbay (PHOREMOST), Prof. J. Bilbro and Dr. E. Arthurs (SPIE), Prof. A. Friberg, Prof. G. von Bally, Prof. Maria Calvo and Prof. A. Friesem (ICO), Prof. K.R. Sreenivasan and Prof. Gallieno Denardo (ICTP) for their important support to the conference ROMOPTO 2006 and to our optics community. 
By the efforts of the scientific advisory committee, coordinated by Prof. $M$. Bertolotti and the programme committee, about 170 scientific papers by authors from 19 countries have been selected for presentation at ROMOPTO 2006, in seven plenary lectures, 36 invited lectures, 52 oral presentations and 76 posters. I express my entire gratitude to the members of these committees, referees, to the invited professors, and to all participants for their high level work. Some of these papers, reviewed by an international referee board, are published in this SPIE Proceedings volume, which hopefully will have a wide distribution and a large interest in the scientific world.

The joy of meeting so many friends at ROMOPTO 2006 was shadowed by the passing from this world of one of the strongest supporters of this conference, Professor Herbert Walther, director and founder of MPQ, Garching, at the end of July. He was an outstanding researcher of the physics of light, an exceptional man and friend, an honored member of the Romanian Academy, and a member of the editorial board of Romanian Reports in Physics. Prof. N. Kroo evocated Herbert's personality in his plenary talk. Shortly after Easter 2007, Acad. loan Ursu, one of the most preeminent Romanian physicists and the initiator of ROMOPTO conferences, passed also from this world. Requiescant in Pace!

I would like to express my thanks to the members of the international scientific advisory committee, programme committee, and organizing committees of ROMOPTO 2006 for their hard work. My gratitude is specially conveyed to Prof. C. Oprean, rector of the University "L. Blaga" of Sibiu, Prof. G. Sofonea, dean of faculty of engineering at "H. Oberth," Prof. I. Isarie, former rector, and to the local organizing team: Prof. V. Petrescu, Prof. Toderita Nemes, Prof. Cl. Isarie, and Mr. V. Fagarasan (University Protocol), all of whom were superb hosts of this conference. Special address and thanks go Dr. R. Medianu, the general director of NILPRP, Dr. Clementina Timus, coordinator of the organizing committee (for her efforts in disseminating information and paper collection), Dr. Adrian Petris (for the important efforts in all steps of conference organization), Dr. Mircea Udrea (for sponsorisations of Coherent Inc. and Apel Laser), and to Doina Nicolae and Camelia Talianu (for design and management of the conference web site), and to my students, Petronela Doia, Tatiana Bazaru, I. Dancus, Alexandra Olteanu, and Mariana Buzatu, for their hard work and efforts in support of this conference.

Finally, I hope that the participants in ROMOPTO 2006 enjoyed the scientific sessions, met their friends in Sibiu, and had the opportunity to start new scientific collaborations. Hopefully also, they will remember their visit in Romania, in the Transylvanian county.

Valentin I. Vlad 


\section{Organized by:}

Romanian Physical Society - Division of Optics and Quantum Electronics - ICO Territorial Committee

SPIE Romania Chapter

National Institute for Laser, Plasma and Radiation Physics - ROCEP

INOE 2000—National Institute of Research \& Development for Optoelectronics

University of Bucharest - Faculty of Physics

University "Lucian Blaga" of Sibiu, Faculty of Engineering "Hermann Oberth" (Romania)

\section{Cosponsoring Institutions:}

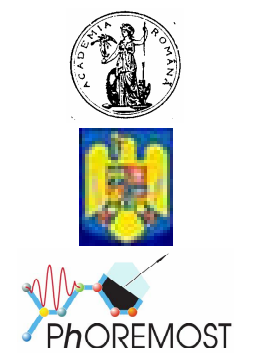

Romanian Academy - Division of Physics

Ministry of Education and Research

European Network of Excellence "PHOREMOST"

Nanophotonics to Realise Molecular Scale Technologies

OSA OSA-Optical Society of America

SPIE Europe

EOARD—European Office of Aerospace Research and Development

ICTP-The "Abdus Salam" International Centre for Theoretical Physics

ICO_-International Commission for Optics

(1) EOS-European Optical Society (EOS)

Institute of Atomic Physics (Romania) 
Downloaded From: https://www.spiedigitallibrary.org/conference-proceedings-of-spie on 26 Apr 2023

Terms of Use: https://www.spiedigitallibrary.org/terms-of-use 


\title{
New Optical Components Based on Nano-scale Features
}

\author{
M. J. Soileau \\ Distinguished Professor of Optics, ECE, and Physics and Vice President for Research, University of \\ Central Florida, Orlando, USA
}

\begin{abstract}
In this talk I will review the research at the College of Optics and Photonics/CREOL, which has led to novel approaches in nanophotonics and which is impacting laser devices and applications.

One of the technologies to be reviewed is based on nano-scale features in photo-thermal-refractive (PTR) glass. PTR glass allows for the production of distributed nano-crystals in the bulk of highly transparent optical glass. These 3-D patterns are holographically produced. Among the applications demonstrated are bulk diffraction gratings, which are highly dispersive, cavity mirrors for extreme wavelength selectivity and stability, beam sampling optics, beam sharing optics, and optics which combine imagery and wavelength selectivity.

The PTR elements produced have the additional properties of high laser damage threshold and environmental stability. Manufacturing processes, optical and mechanical properties, and specific results from various applications will be presented.
\end{abstract}




\title{
Semiconductor pumped cw solid-state lasers in the visible and UV spectral region
}

\author{
Guenter Huber \\ Institut für Laser-Physik, Universität Hamburg, Germany
}

\begin{abstract}
Intracavity frequency conversion of near IR solid-state lasers efficiently yields coherent visible radiation. Furthermore, semiconductor pumped Er-, Yb, Pr- up-conversion lasers and direct pumped Pr- lasers operate on fundamental visible modes offering simple and efficient nonlinear UV-generation.
\end{abstract}




\title{
Inorganic nanotubes and inorganic fullerene-like materials: state of the art (from concept to applications)
}

\author{
Reshef Tenne \\ Department of Materials and Interfaces, Weizmann Institute, Israel
}

\begin{abstract}
We have proposed in 1992 that nanoparticles of layered compounds will be unstable against folding and close into fullerene-like structures and nanotubes $(I F)$. Initially this hypothesis was realized in $\mathrm{WS}_{2}, \mathrm{MoS}_{2}$ and the respective diselenides. Subsequently, nanotubes and fullerene-like structures were prepared from numerous compounds with layered and recently also non-layered structure by various groups. Much progress has been achieved in the synthesis of inorganic nanotubes and fullerene-like nanoparticles of $\mathrm{WS}_{2}$ and $\mathrm{MoS}_{2}$ and many other metal dichalcogenides over the last few years. Synthetic methods for the production of multiwall $\mathrm{WS}_{2}$ nanotubes by sulfidizing $\mathrm{WO}_{3}$ nanoparticles have been described and further progress is underway. A fluidized-bed reactor for the synthesis of up to $100 \mathrm{~g} / \mathrm{day}$ of fullerene-like $\mathrm{WS}_{2}$ nanoparticles has been established in our lab, and the scaling-up of the synthesis to $100 \mathrm{~kg} / \mathrm{day}$ and beyond is under way. The detailed mechanisms for the synthesis of fullerene-like $\mathrm{WS}_{2}$ and $\mathrm{MoS}_{2}$ nanoparticles and nanotubes of these compounds have been elucidated.

Substantial progress has been accomplished in the use of such nanoparticles for tribological applications and lately for e.g. impact resilient materials for self-protection. Numerous testing programs have been undertaken jointly with different laboratories and major industrial partners and have clearly indicated the usefulness of the fullerene-like $\mathrm{WS}_{2}\left(\mathrm{MoS}_{2}\right)$ as solid lubricants in various products. These tests indicated that $I F-\mathrm{MoS}_{2}$ and $I F-\mathrm{WS}_{2}$ are heading for large scale applications in the automotive, machining, aerospace, electronics, medical and numerous other kinds of industries. This technology was licensed to "ApNano Materials, Inc." ("NanoMaterials, Ltd."), which is currently involved in many collaborative development programs. Novel applications of inorganic nanotubes and fullerene-like nanoparticles in the fields of catalysis; microelectronics; Li rechargeable batteries; medical and opto-electronics will be presented.
\end{abstract}




\title{
Advances in mapping and steering of functional organic molecules by nonlinear optics from micron to single molecule scale
}

\author{
Joseph Zyss*, Gabriel Dutier, Sophie Brasselet \\ Molecular Quantum Photonics Laboratory and d'Alembert Institute, Ecole Normale Supérieure \\ Cachan, France
}

\begin{abstract}
We will report all the way from principles to latest advances, of a new approach to molecular nonlinear optics whereby nonlinear light-molecule interactions are used to encode information in molecular matter, rather than simply probe the nonlinear behaviour of molecular systems. This approach is based on the recognition of the angular dependence of generalized multiphoton interaction selection rules, by virtue of which specific sub-set of molecules in a priori random organization can be selectively addressed. Demonstrations on various molecular systems and states of matter (crystal, polymers with various degrees of orders) at micron and nanoscales will be emphasized.
\end{abstract}

